\title{
RESENHA:
}

\section{AS POLÍTICAS EDUCACIONAIS E SUAS DIFERENTES LENTES DE ANÁLISE THE EDUCATION POLICIES AND ITS DIFFERENT ANALYTICAL LENSES}

GULSON, Kalervo N.; CLARKE, Matthew; PETERSEN, Eva Bendix (Eds.). Education policy and contemporary theory: implications for research. London: Routledge, 2015.

O livro traz uma introdução intitulada "Teoria, política, metodologia", escrita por Kalervo N. Gulson, Matthew Clarke e Eva Bendix Petersen, e indaga acerca do que seja teoria e os estudos de política da educação, sugerindo teoria como um conjunto de hipóteses sobre como o mundo funciona. Sobre os estudos de política da educação, os autores afirmam que não é possível fornecer uma definição pura, dando espaço para que esses estudos sejam várias coisas, principalmente, coisas diferentes do que habitualmente chamamos de estudos de pesquisas da educação.

O primeiro capítulo, "Bourdieu e o fazer político sociológico na educação", é de Shaun Rawolle, Universidade Deakin, Austrália, e de Bob Lingard, Universidade de Queensland, Austrália. Os autores tratam o diálogo a partir da teoria social da prática e do campo de Pierre Bourdieu. Para tanto, colocam como chave para suas discussões a flexibilidade teórica de Bourdieu, com rejeição ao teoricismo. Observa-se na construção teórica dos autores o encaminhamento para uma perspectiva cíclica das políticas, dando um sentido de circularidade nos textos e discursos, o que aparentemente demonstra uma crítica à perspectiva estadocêntrica.

O segundo capítulo, "Michel de Certeau, vida cotidiana e os estudos políticos culturais na educação", de Sue Saltmarsh, Universidade Católica da Austrália, dialoga com a abordagem dos estudos culturais para a política. Informada pelo teórico cultural Michel de Certeau, a autora considera como as teorias e metodologias relacionadas com o cotidiano podem iluminar a dinâmica das culturas políticas. Argumenta que as abordagens culturais para a análise de políticas públicas precisam ser fundamentadas na compreensão das atividades cotidianas e práticas de construção de significado daqueles que são os fabricantes, analistas, beneficiários, implementadores finais da política.

No terceiro capítulo, "Recorrendo a Deleuze e Guattari: em direção a uma política do método em estudos de política educacional", de Sam Sellar, Universidade de Queensland, Austrália, reflete-se o trabalho de Deleuze e Guattari. O autor aborda as relações entre as práticas de análise de políticas em

\footnotetext{
* Professor do Programa de Pós-Graduação em Ensino e Relações Étnico-Raciais - PPGER, do Instituto de Humanidades, Artes e Ciências - IHAC, da Universidade Federal do Sul da Bahia (UFSB). E-mail: paulodetassio.silva@,ufsb.edu.br
} 
que a teoria social está em primeiro plano, e práticas através das quais os dados sociais são produzidos e utilizados para fins de política. O diálogo permite-nos pensar uma política do método em que o dado esteja descentrado na pesquisa, sendo tratado como rizoma, a-centrado, com redes de autômatos infinitos.

O quarto capítulo, "Derrida: a 'impossibilidade’ desconstruindo a política educacional promulgada", de Greg Vass, Universidade de New South Wales, Austrália, propõe discutir a desconstrução em Derrida, e para isso começa questionando o modelo formal de escrita acadêmica e a invocação do sentido de privilégio à palavra falada. Utilizando-se da carta como gênero textual, convida a refletir sobre a derrapagem temporal e contextual que ocorre no ato de escrever. A discussão de justiça social perseguida pela educação abordada no capítulo nos permite um diálogo com Macedo (2014) em suas pesquisas realizadas no campo do currículo no Brasil, ao pontuar que: “[...] as tentativas de articulação entre igualdade e diferença se constituem em um problema para a educação, na medida em que tal articulação somente pode ser pensada num contexto em que o sentido de diferença e reduzido à diversidade" (MACEDO, 2014, p. 86).

O quinto capítulo, "Políticas educacionais como formações discursivas: uma ótica foucaultiana", é de Eva Bendix Petersen, Universidade Roskilde, Dinamarca. A autora adota a perspectiva discursiva de Foucault, pontuando que as políticas se construíram como uma forma moderna de governar à distância. Para tanto, a mesma recorre à descrição de Foucault de como as tecnologias governamentais são alteradas a partir do século XVI, do espetáculo da execução pública para o trivial, mas em alguns aspectos tecnológicos não humanos, como as prisões e as escolas. A noção de formação política da autora trabalha com a ideia de que qualquer política é um tanto limitada, podendo ser composta de vários discursos, inclusive concorrentes.

O sexto capítulo, "Perspectivas Lacanianas na análise da política educacional", é de Matthew Clarke, Universidade York St John, Reino Unido. O autor assume que a teoria psicanalítica talvez não seja a candidata mais óbvia a ser utilizada como recurso para uma análise política. Contudo, a discussão colaboraria em esboçar linhas de análise, por exemplo, na ideia de identificação do fantasmático, causasobjetos fantasmáticos ou sublimes do desejo em torno dos quais determinados discursos políticos são pivôs. Deslocando a ideia de sujeito/sociedades do conhecimento para sujeitos/sociedades do desejo, o autor analisa como a operação da fantasia, medos e anseios fantasmáticos podem ser usados para explicar fenômenos como a fixação da política neoliberal obsessiva e repetida em significantes, como a produtividade e o crescimento, como fantasmáticos objetos-causa do desejo da organização do campo social e simbólico.

O capítulo sétimo, "Situada, relacional e prático-orientada: a abordagem da teoria ator-rede", de Radhika Gorur, Victoria University, Austrália, inicia informando que a teoria ator-rede não é uma teoria política, contudo, tem muito a oferecer aos desejos de um pesquisador político. Neste sentido, a teoria ator-rede é uma abordagem semiótica material que oferece recursos teóricos e metodológicos, que 
direcionam a atenção para as práticas que criam, mobilizam, sustentam ou desafiam as relações entre atores em qualquer fenômeno social.

O oitavo capítulo, "Pensando a política e a gestão da educação a partir do conceito de afetos", é de Dorthe Staunces e Justine Gronbcek Pors, Universidade Aarhus, Dinamarca. O capítulo explora uma leitura metodológica a partir do conceito de afetos em pesquisas empíricas na política educacional, apontando que a priori o conceito de afeto chamaria atenção para paixões avassaladoras e sentimentos que poderiam se vincular a raiva, vergonha, alegria e confiança. No entanto, afetos permitem também pensar de forma ampla as tensões e cobranças de energias trocadas e movidas, por exemplo, num programa internacional de avaliação como o PISA.

O capítulo nove, "Teoria assemblage e política educacional sociológica", de Deborah Youdell, Universidade de Birmingham, Reino Unido, propõe no texto um movimento da política sociológica para a etnografia da assemblage, tendo como compreensão que as formas produtivas são mutáveis e complexas, e que as formações sociais da política são apenas componentes. Para Youdell, a ideia de assemblage de Deleuze e Guatarri nos ajuda a conceituar o terreno complexo da educação, podendo significar na educação o mapeamento dos detalhes das características, movimentos e interações produtivas entre uma gama de componentes que incluem dinheiro, orientações políticas, meios e climas populares, políticas de legislação, acordos institucionais, o conhecimento formal e informal, subjetividades, pedagogias, práticas cotidianas e sentimentos.

O décimo capítulo, "Counterpublics, crise e crítica: uma abordagem sócio-histórica feminista para a pesquisa política", de Jessica Gerrard, Universidade de Melbourne, Austrália, inicia dizendo que as políticas saturam as práticas educativas uma vez que se propõem a analisar a política na relação das lutas. As políticas representam instâncias oficiais de significado e intenção, onde governos e instituições usam políticas como um meio para dar forma e prática direta, e para indicar posições ou significados particulares. Não obstante, pontua que as políticas também são influenciadas por subprodutos e produtos das mais amplas lutas sociais, culturais e políticas, incidindo práticas e significados para educação.

O décimo primeiro capítulo, "Encarnando estudos de política: a genealogia feminista como metodologia", é apresentado por Wanda S. Pillow, Universidade de Utah, EUA. O capítulo reflete o Título IX da Lei Federal dos Estados Unidos, que pró́be a discriminação dos direitos civis de gênero na educação, que completou 40 anos em 2012. O texto busca considerar o impacto e a eficácia das políticas públicas por igualdade de gênero. Para tanto, introduz a discussão a partir dos termos feminismo, concretização e genealogia, conceituados dentro da genealogia feminista como uma política de estudo metodológico.

O décimo segundo capítulo, "Governamentalidade: conceito de Foucault para o nosso raciocínio político moderno", tem como autor Kaspar Villadsen, Universidade de Copenhagen, Dinamarca. O autor coloca que, ao se integrarem métodos etnográficos com os estudos de governamentalidade, torna-se possível investigar com maiores detalhes as lutas de poder travadas em torno de categorias discursivas 
em contextos sociais e organizacionais específicos. Neste sentido, torna-se possível visualizar categorias discursivas como instáveis uma vez que elas são praticadas, negociadas e contornadas.

O décimo terceiro capítulo tem como título "Tomando um 'rumo material' na pesquisa política da educação", de Stephen Heimans, Universidade de New England, Austrália. Com um enfoque metodológico, o texto apresenta a ideia de que agentes políticos não são meramente humanos, mas assemblages precárias, o que aponta para diferentes análises na investigação de políticas da educação. Para o autor, a tomada de um "rumo material" nas pesquisas da política da educação abre o espaço para um interesse ativo em interromper a produção de provas "fáceis" que podem diretamente ser manipuladas em um quadro utilitarista.

O décimo quarto capítulo, "Paradigma da Mobilidade e pesquisas em educação", é de autoria de Fazal Rizvi, Universidade de Melbourne, Austrália. O autor coloca que noções de mobilidade, movimento e fluxos devem ser tratadas como centrais na compreensão dos processos globais que reconstituem as comunidades, as instituições sociais e as vidas das pessoas. Isto requer repensar os processos contemporâneos de formação social e política, bem como abordagens de investigação social, aplicandoos às pesquisas de políticas em educação, uma vez que os sistemas nacionais de educação são profundamente afetados pelas dinâmicas de deslocamentos.

O décimo quinto capítulo, "Uma abordagem narrativa para a análise de políticas", é de Peter Bansel, Universidade de Western Sydney, Austrália. O autor busca articular no texto algumas possibilidades metodológicas e teóricas para trabalhar a narrativa como uma abordagem à política e à sua análise. Para tanto, coloca que uma abordagem narrativa para a análise da política centra-se em compreender questões políticas, problemas e definições que colocam em primeiro plano as formas em que particulares "histórias de influência", ou narrativas de política, passam a dominar o processo político, e na medida em que significam e sugerem ação, objetivam um curso de ação como se fosse independente de um autor específico ou narrador.

O décimo sexto capítulo, "Teoria Queer, política e educação", tem autoria de Mary Lou Rasmussen, Universidade de Monash, Austrália e Christina Gowlett, Universidade de Queensland, Austrália. As autoras atentam para o fato de que a teoria queer tem sido muitas vezes amarrada a assuntos de gênero e sexualidade e às narrativas de progresso político. Pontuam que apesar de muitos projetos criativos que interrogam prazeres de ensino e aprendizagem, ou repensam as implicações da pesquisa queer, estes muitas vezes se apresentam limitados pela imaginação do pesquisador sobre a necessidade de um "sujeito" da investigação queer, vinculado a idéias particulares de progresso educacional e político.

O décimo sétimo capítulo tem como título "Pensando rizomaticamente: usando Deleuze em contextos de política de educação", de Eileen Honan, Universidade de Queensland, Austrália. A autora propõe a reflexão de métodos analíticos associados a textos, discursos e análises como rizomas. Tem como proposta uma análise rizo-textual, a partir da ideia de rizoma, que segundo a mesma oferece uma leitura da agência do trabalho docente, num caminho em que os professores dialogam com os 
documentos políticos curriculares. Para Honan, trata-se de pensar com Deleuze sobre como o trabalho dos professores, e suas relações com os textos, e textos de política em particular, achatam as hierarquias de um envelope de binários de conformidade, subserviência, competência e perícia.

O décimo oitavo capítulo, "Espaço relacional e análise política da educação", é de autoria de Kalervo N. Gulson, Universidade de New South Wales, Austrália. O capítulo chama atenção para a relação da política no espaço e no tempo, entendendo que a política educativa possui uma intervenção temporal no mundo, concentrando-se no período de desenvolvimento, no cronograma para e execução da política, nos anos de maturação até a avaliação, entre outros processos, indagado se a política seria sempre uma forma de ordenamento espacial.

O livro se encerra no décimo oitavo capítulo, sendo importante frisar a riqueza da obra na apresentação de abordagens teóricas e metodológicas, que podem ser refletidas nos contextos das políticas educacionais, oferecendo teorias e abordagens que circulam no campo, o que pode contribuir para pesquisadores (as) que se iniciam em pesquisas deste tipo, e até mesmo aqueles que desejam conhecer outras maneiras de pesquisar. Neste sentido, os empreendimentos lançados pelos (as) autores (as) na construção de abordagens metodológicas cambiantes, talvez sejam as mais importantes contribuições do livro.

\section{Referências}

MACEDO, Elizabeth. Currículo, cultura e diferença. In: LOPES, Alice C.; ALBA, Alícia de. Diálogos curriculares entre Brasil e México. Rio de Janeiro: EDUERJ, 2014, p. 83- 101. 